\title{
Strategies for improved rhamnolipid production by Pseudomonas aeruginosa PA1
}

Alexandre Soares dos Santos, Nei Pereira Jr, Denise M G Freire

Rhamnolipids are biosurfactants with potential for diversified industrial and environmental uses. The present study evaluated three strategies for increasing the production of rhamnolipid-type biosurfactants produced by Pseudomonas aeruginosa strain PA1. The influence of $\mathrm{pH}$, the addition of $P$. aeruginosa spent culture medium and the use of a fedbatch process were examined. The culture medium adjusted to $\mathrm{pH} 7.0$ was the most productive. Furthermore, the $\mathrm{pH}$ of the culture medium had a measurable effect on the ratio of synthesized mono- and dirhamnolipids. At $\mathrm{pH}$ values below 7.3, the proportion of monorhamnolipids decreased from 45 to $24 \%$. The recycling of $20 \%$ of the spent culture medium in where $P$. aeruginosa was grown up to the later stationary phase was responsible for a $100 \%$ increase in rhamnolipid volumetric productivity in the new culture medium. Finally, the use of fed-batch operation under conditions of limited nitrogen resulted in a 3.8-fold increase in the amount of rhamnolipids produced ( 2.9 g.L.-1 to 10.9 $\left.g . L^{-1}\right)$. These results offer promising pathways for the optimization of processes for the production of rhamnolipids. 
1 Strategies for improved rhamnolipid production by Pseudomonas aeruginosa PA1

\section{Alexandre S. Santos ${ }^{1 *}$, Nei Pereira $\mathrm{Jr}^{2}$ and Denise M. G. Freire ${ }^{3}$}

$3{ }^{1}$ Departamento de Ciências Básicas, Universidade Federal dos Vales do Jequitinhonha e Mucuri,

4 Diamantina, MG, Brazil; ${ }^{2}$ Departamento de Engenharia Bioquímica, Escola de Química,

5 Universidade Federal do Rio de Janeiro, Rio de Janeiro, RJ, Brazil.; ${ }^{3}$ Departamento de

6 Bioquímica, Instituto de Química, Universidade Federal do Rio de Janeiro, Rio de Janeiro, RJ,

Brazil

Send correspondence to: Alexandre S. Santos. Departamento de Ciências Básicas.

Universidade Federal dos Vales do Jequitinhonha e Mucuri, Campus JK. Rodovia MGT 367 -

12 alexandre.soares@ufvjm.edu.br 


\section{Abstract}

Rhamnolipids are biosurfactants with potential for diversified industrial and environmental uses. The present study evaluated three strategies for increasing the production of rhamnolipidtype biosurfactants produced by Pseudomonas aeruginosa strain PA1. The influence of $\mathrm{pH}$, the addition of $P$. aeruginosa spent culture medium and the use of a fed-batch process were examined. The culture medium adjusted to $\mathrm{pH} 7.0$ was the most productive. Furthermore, the $\mathrm{pH}$ of the culture medium had a measurable effect on the ratio of synthesized mono- and dirhamnolipids. At $\mathrm{pH}$ values below 7.3, the proportion of monorhamnolipids decreased from 45 to $24 \%$. The recycling of $20 \%$ of the spent culture medium in where $P$. aeruginosa was grown up to the later stationary phase was responsible for a $100 \%$ increase in rhamnolipid volumetric productivity in the new culture medium. Finally, the use of fed-batch operation under conditions of limited nitrogen resulted in a 3.8-fold increase in the amount of rhamnolipids produced ( $2.9 \mathrm{~g}$ $\mathrm{L}^{-1}$ to $10.9 \mathrm{~g} \mathrm{~L}^{-1}$ ). These results offer promising pathways for the optimization of processes for the production of rhamnolipids.

\section{Keywords -}




\section{Introduction}

Rhamnolipids are biodegradable biological surfactants. They present low toxicity and high resistance to extreme conditions of $\mathrm{pH}$, salinity and temperature (Kesting et al., 1996). Their surface properties, such as emulsification, dispersion, foaming, detergency, wetting and stabilization (Van Dyke et al., 1993; Ishigami et al., 1994; Desai and Banat, 1997; Bognolo, 1999), as well as their capacity for removing heavy metals (Torrens et al., 1998; Lang and Wullbrandt, 1999; Kitamoto et al., 2002) and their anticorrosive capacities (Araujo et al., 2013), confer to these biosurfactants a variety of ecological (Rahman et al., 2002) and commercial applications in the oil, pharmaceutical, food and chemical industries (Irfan-Maqsood and SeddiqShams, 2014; Randhawa et al., 2014; Sinumvayo and Ishimwe, 2015).

Rhamnolipids are mainly produced by Pseudomonas aeruginosa, a Gram-negative bacterium that can be isolated from various habitats (water, soil or even plants). The control of rhamnolipid production in $P$. aeruginosa is achieved by a regulatory system called quorum sensing that is controlled by autoinducers such as acyl homoserine lactones and Pseudomonas quinolone signal molecule. These signaling molecules, paired with the LasR and RhlR regulators, initiate the expression of the enzymes involved in rhamnolipid synthesis (rhamnosyltransferases) (Ochsner et al., 1994, 1995; Rahim et al., 2001; Reis et al., 2011).

Efforts should be oriented toward the optimization of processes for the production of biosurfactants that result in high productivity on a commercial scale so that they can compete with synthetic surfactants in terms of cost. One of the strategies that has been suggested in the literature is the limitation of nutrients (Desai and Banat, 1997; Chayabutra et al., 2000), mainly nitrogen sources, as well as multivalent cations (Syldatk et al., 1985; Glick et al., 2010) and some anions (Mulligan et al., 1989; Clarck et al., 2010), as a condition necessary for stimulating 
56 the synthesis of rhamnolipids by $P$. aeruginosa. In addition to nutritional modifications, changes

57 in physical factors such as temperature and $\mathrm{pH}$ can also influence the synthesis of rhamnolipids

58 by P. aeruginosa (Souza et al., 2011; Jamal et al., 2014). Another approach to the induction of

59 the rhamnolipid synthesis is the use of exogenous or endogenous autoinducers (Ochsner and

60 Reiser, 1995; Nakata et al., 1998; Galkin et al., 2014).

61 The aim of this work was to improve the cultivation conditions for the production of 62 rhamnolipids by a strain of Pseudomonas aeruginosa isolated from a Brazilian petroleumexploring environment. This study involved the investigation of the effect of a variation in the $\mathrm{pH}$ of the culture medium, the medium supplementation with recycled $P$. aeruginosa spent culture medium and evaluation of process carried on fed-batch operation.

\section{Material and Methods}

\section{Inoculum}

Pseudomonas aeruginosa PA1 (Santa Anna et al., 2001) was maintained in a glycerol solution $(10 \% \mathrm{v} / \mathrm{v})$ at $-80^{\circ} \mathrm{C}$. The thawed strain sample was inoculated onto YPDA plates (yeast extract, $0.3 \%$; peptone, $1.5 \%$; dextrose, $0.1 \%$; agar, $1.2 \%$ ) at $30^{\circ} \mathrm{C}$ for $48 \mathrm{~h}$. The growth of the inoculum was initiated by the addition of a loopful of cells from YPDA plates to a $1000 \mathrm{~mL}$ Erlenmeyer flask containing $300 \mathrm{~mL}$ of medium with the following composition (per liter): $1.0 \mathrm{~g}$ of $\mathrm{NaNO}_{3}, 3.0 \mathrm{~g}$ of $\mathrm{KH}_{2} \mathrm{PO}_{4}, 7.0 \mathrm{~g}$ of $\mathrm{K}_{2} \mathrm{HPO}_{4}, 0.2 \mathrm{~g}$ of $\mathrm{MgSO}_{4} .7 \mathrm{H}_{2} \mathrm{O}, 5.0 \mathrm{~g}$ of yeast extract, 5.0 $\mathrm{g}$ of peptone, and $30 \mathrm{~g}$ of glycerol. P. aeruginosa was grown at $30^{\circ} \mathrm{C}$ and $\mathrm{pH} 7.0$ in a rotary shaker at $170 \mathrm{rpm}$ for 24 hours. Cells were harvested by centrifugation $(10,000 \mathrm{~g}$ for 30 minutes) and used as the inoculum. 


\section{Influence of pH on rhamnolipid production}

The culture medium contained (per liter) $0.2 \mathrm{~g}$ of $\mathrm{MgSO}_{4} 7 \mathrm{H}_{2} \mathrm{O}, 1.38 \mathrm{~g}$ of $\mathrm{NaNO}_{3}$, and $30 \mathrm{~g}$ of glycerol. The $\mathrm{pH}$ of the culture medium was adjusted from 5.7 to 8.0 with $\mathrm{KH}_{2} \mathrm{PO}_{4} / \mathrm{K}_{2} \mathrm{HPO}_{4}$ buffer by varying the mole fraction of salt species without changing the concentration of total phosphate ion, which was maintained at 0.062 moles per liter. Six 500-mL Erlenmeyer flasks containing a working volume of $100 \mathrm{~mL}$ were prepared, inoculated with $0.12 \mathrm{~g}$ of cells (dry weight) and incubated at $30{ }^{\circ} \mathrm{C}$ in a rotary shaker at $170 \mathrm{rpm}$ for 192 hours. Samples were removed at 24-hour intervals for the measurement of cell growth and rhamnolipid concentration.

\section{Simple batch process supplemented with recycled $P$. aeruginosa spent culture medium}

The culture medium was prepared with the following composition (per liter): $1.38 \mathrm{~g}$ of $\mathrm{NaNO}_{3}, 3.0 \mathrm{~g}$ of $\mathrm{KH}_{2} \mathrm{PO}_{4}, 7.0 \mathrm{~g}$ of $\mathrm{K}_{2} \mathrm{HPO}_{4}, 0.2 \mathrm{~g}$ of $\mathrm{MgSO}_{4} \cdot 7 \mathrm{H}_{2} \mathrm{O}$, and $30 \mathrm{~g}$ of glycerol. To each of five 500-mL Erlenmeyer flasks was added $100 \mathrm{~mL}$ of liquid medium supplemented with $1 \%$, $5 \%, 10 \%, 15 \%$ or $20 \%(\mathrm{v} / \mathrm{v})$ of cell-free spent culture supernatant from a $120 \mathrm{~h}$-old $P$. aeruginosa PA1 culture. The control flask contained no spent culture medium. The flasks were inoculated with $0.05 \mathrm{~g}$ of cells (dry weight) and incubated at $30^{\circ} \mathrm{C}$ and $\mathrm{pH} 7.0$ in a rotary shaker at $170 \mathrm{rpm}$ for 200 hours. Aliquots $(1.5 \mathrm{~mL})$ were removed at 24-hour intervals for the assessment of cell growth and rhamnolipid production. The mass balance (carbon and nitrogen sources) present at the start of the culture process was adjusted, when necessary, to maintain the same $\mathrm{C} / \mathrm{N}$ ratio and avoid undesirable side effect.

\section{Fed-batch process: nitrogen and carbon feed}

The culture medium contained (per liter) $3.0 \mathrm{~g}$ of $\mathrm{KH}_{2} \mathrm{PO}_{4}, 7.0 \mathrm{~g}$ of $\mathrm{K}_{2} \mathrm{HPO}_{4}, 0.2 \mathrm{~g}$ of $\mathrm{MgSO}_{4} .7 \mathrm{H}_{2} \mathrm{O}, 0.46 \mathrm{~g}$ of $\mathrm{NaNO}_{3}$, and $10.0 \mathrm{~g}$ of glycerol. The $\mathrm{pH}$ was adjusted to 7.0. Three 500 - 
mL Erlenmeyer flasks (A, B and C) were prepared containing $100 \mathrm{~mL}$ of the liquid medium. The flasks were inoculated with $0.2 \mathrm{~g}$ of cells (dry weight) and incubated at $30^{\circ} \mathrm{C}$ in a rotary shaker at $170 \mathrm{rpm}$ for 240 hours. The frequency of addition of nutrients was a function of the amount of glycerol consumed in each flask. Flask A received $5 \mathrm{~mL}$ of a solution containing glycerol (200 g. $\left.\mathrm{L}^{-1}\right)$ and sodium nitrate $\left(9\right.$ g. $\left.\mathrm{L}^{-1}\right)$ at each addition. Flask $\mathrm{B}$ received $5 \mathrm{~mL}$ of a solution containing only glycerol (200 g... $\left.\mathrm{L}^{-1}\right)$, and flask C received $5 \mathrm{~mL}$ of sterile distilled water. Aliquots $(1.5 \mathrm{~mL})$ were removed at 24-hour intervals for the quantification of cell growth, nitrate and glycerol consumption and rhamnolipid production.

\section{Thin-layer chromatography for analysis of rhamnolipid types}

The rhamnolipids produced were extracted with ethyl acetate from acidified ( $\mathrm{pH}$ 2.0) cellfree medium and analyzed by TLC on silica-gel-coated aluminum sheets (Macherey-Nagel®) using $\mathrm{CHCl}_{3}: \mathrm{CH}_{3} \mathrm{OH}: \mathrm{CH}_{3} \mathrm{COOH}(65: 15: 2)$ as the eluent (Schenk et al., 1995). The separated zones were stained with orcinol-sulfuric acid reagent, followed by heating at $100{ }^{\circ} \mathrm{C}$ for 15 minutes. The stained plates were scanned, and the relative quantities of the spots corresponding to the monorhamnolipids and dirhamnolipids were determined by densitometry using Band Leader (Ma'ayan Aharoni) and Micronal Origin (Micronal Software, Inc) software to produce two dimensional chromatograms.

\section{Determination of cell, rhamnolipid, glycerol and nitrate concentrations}

Cell growth was assessed by measuring the absorbance at $500 \mathrm{~nm}$, and the cell dry weight

(g.L $\left.\mathrm{L}^{-1}\right)$ was determined using a standard calibration curve $\left[\mathrm{ABS}=1.2595 \mathrm{x}\right.$ DW $\left(\mathrm{g} . \mathrm{L}^{-1}\right)-$ $\left.\mathrm{R}^{2}=0.989\right]$, considered to be valid for absorbance values up to 0.6 OD. Rhamnolipid 
126 quantification was achieved indirectly by measurement of the rhamnose concentration using the 127 method of Dubois (1956) and was expressed as the rhamnolipid concentration using the factor 2.23 established by Kronemberger et al. (2008) by mass spectrometry measurements. A $0.5 \mathrm{~mL}$ volume of cell-free supernatant was mixed with $0.5 \mathrm{~mL}$ of $5 \%$ phenol solution and $2.5 \mathrm{~mL}$ of $98 \%$ sulfuric acid and incubated for 15 minutes before measuring the absorbance at $490 \mathrm{~nm}$. The results were compared with the analytical curve for rhamnose. Glycerol was quantified by the GPO-POD enzymatic-colorimetric method using a kit for triglyceride determination from LaborLab ${ }^{\circledR}$ (Brazil). Nitrate was quantified through a colorimetric method using brucine sulfate (ACS, 2006). Briefly, $2 \mathrm{~mL}$ of 0.6 g.L.-1 brucine sulfate in sulfuric acid solution (80\%) was added to $0.5 \mathrm{~mL}$ of sample, and the reaction mixture was heated in boiling water for 15 minutes. The reaction mixture was immediately cooled in an ice bath, and the absorbance was measured at 410 nm. The absorbance values were converted into concentration using an analytical curve for sodium nitrate.

\section{Definition of process parameters utilized}

The process parameters utilized to evaluate the progress of improvement strategies for rhamnolipid production are defined as follows. $\mathbf{t}_{\mathbf{f}}$ : final time of process $(h)$; $\mathbf{t}_{\mathbf{i}}$ : initial time of process $(\mathrm{h}) ; \Delta \mathbf{t}\left(\mathrm{t}_{\mathrm{f}}-\mathrm{t}_{\mathrm{i}}\right) ; \mathbf{P}_{\mathrm{f}}$ : final rhamnolipid concentration $\left(\mathrm{g} . \mathrm{L}^{-1}\right) ; \mathbf{P}_{\mathrm{i}}$ : initial rhamnolipid concentration (g.L $\left.{ }^{-1}\right) ; \mathbf{X}_{\mathbf{i}}$ : initial cell mass concentration $\left(\mathrm{g} . \mathrm{L}^{-1}\right) ; \mathbf{X}_{\mathbf{f}}$ : final cell mass concentration (g.L $\left.{ }^{-1}\right) ; \mathbf{S}_{\mathbf{f}}$ : final substrate concentration $\left(\right.$ g. $\left.\mathrm{L}^{-1}\right) ; \mathbf{S}_{\mathbf{i}}$ : initial substrate concentration (g.L $\left.{ }^{-1}\right)$; $\Delta$ Rhamnolipids $\left(\mathrm{P}_{\mathrm{f}}-\mathrm{P}_{\mathrm{i}}\right) ; \Delta$ Biomass $\left(\mathrm{X}_{\mathrm{f}}-\mathrm{X}_{\mathrm{i}}\right) ; \Delta$ Substrate $\left(\mathrm{S}_{\mathrm{i}}-\mathrm{S}_{\mathrm{f}}\right) ; \mathrm{Y}_{\mathbf{P} / \mathbf{X}}(\Delta$ Rhamnolipids $\div$

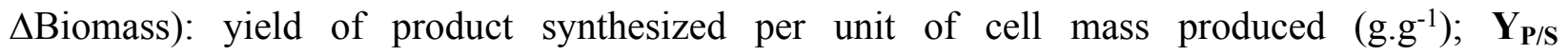
( $\Delta$ Rhamnolipids $\div \Delta$ Substrate): yield of product synthesized per unit of substrate consumed (g.g- 
$\left.149{ }^{1}\right) ; \mathbf{Q}_{\mathbf{P}}(\Delta$ Rhamnolipids $\div \Delta \mathrm{t})$ : volumetric rhamnolipid production rate $\left(\mathrm{g} \cdot \mathrm{L}^{-1} \cdot \mathrm{h}^{-1}\right) ; \mathbf{Q}_{\mathbf{S}(\mathbf{G l y})}$ $150(\Delta$ Substrate $\div \Delta \mathrm{t})$ : volumetric glycerol consumption rate $\left(\mathrm{g} \cdot \mathrm{L}^{-1} \cdot \mathrm{h}^{-1}\right) ; \mathbf{Q}_{\mathrm{S}(\mathrm{NO3})}(\Delta$ Substrate $\div \Delta \mathrm{t})$ : 151 volumetric nitrate consumption rate $\left(\mathrm{g} \cdot \mathrm{L}^{-1} \cdot \mathrm{h}^{-1}\right) ; \mathbf{q}_{\mathbf{P}}\left(\mathrm{Y}_{\mathrm{P} / \mathrm{X}} \times 1000 \div \Delta \mathrm{t}\right)$ : specific rate of 152 rhamnolipids synthesis $\left(\mathrm{mg} \cdot \mathrm{g}^{-1} \cdot \mathrm{h}^{-1}\right)$;

153

\section{Results and Discussion}

\section{Influence of pH on rhamnolipid synthesis}

The qualitative effect of $\mathrm{pH}$ on rhamnolipid synthesis was evaluated by thin layer chromatography. Densitometric analysis of mono- and dirhamnolipids performed by TLC (Figure 1) furnished relative migration values close to 0.8 for the monorhamnolipids and 0.5 for the dirhamnolipids. These values are in agreement with the migration rate of monorhamnolipids and dirhamnolipids observed by Schenk and collaborators (1995), who employed TLC analysis under the same conditions. Under the assay conditions, the more hydrophilic dirhamnolipids interact more strongly with the TLC (silica gel) stationary phase because of the presence of two rhamnose rings linked to lipid chain, whereas only one sugar ring exists in the monorhamnolipids species. 

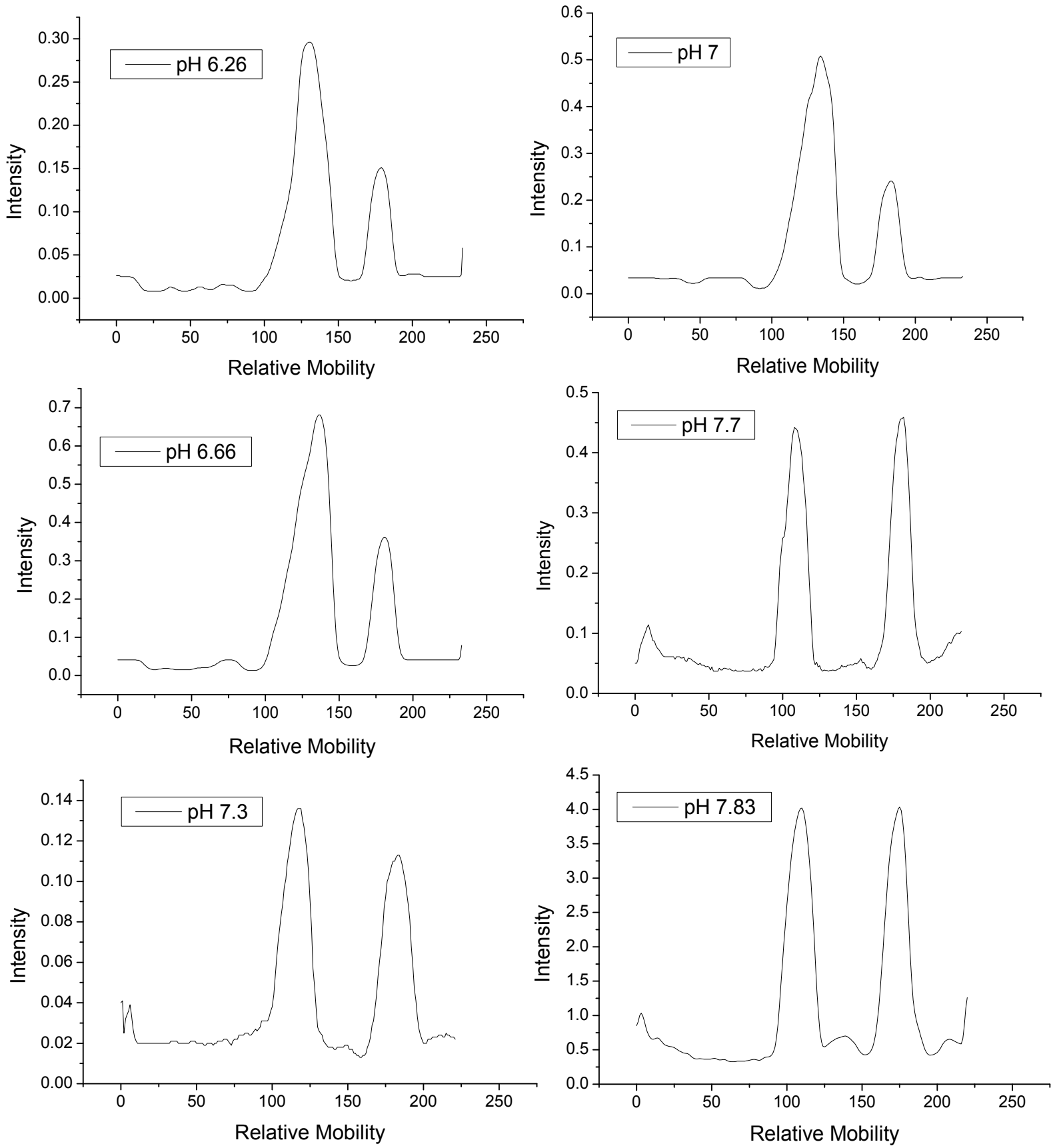

165

Figure 1: Densitometry of the thin layer chromatographs of rhamnolipids synthesized in culture medium at different $\mathrm{pH}$ values. 
As is shown in the Table 1, the percentage of mono- and dirhamnolipids, determined by the amount of monorhamnolipids produced was lower than the amount of dirhamnolipids. On the other hand, at $\mathrm{pH}$ values higher than 7.0, the amounts of mono- and dirhamnolipids were approximately the same. Mata-Sandoval, Karns and Torrens (2001) showed that, at pH 6.26 and 7.0, dirhamnolipids were the most abundant molecular species in the mixtures of rhamnolipids synthesized by $P$. aeruginosa with corn oil as sole carbon source. However, they limited their experiments up to $\mathrm{pH}$ 7.0.

Table 1: Relative percentages of the rhamnolipid types synthesized as a function of the $\mathrm{pH}$ of the 179 culture medium.

\begin{tabular}{ccc}
\hline $\mathbf{p H}$ & Dirhamnolipids (\%) & Monorhamnolipids (\%) \\
\hline 6.26 & 74.35 & 25.65 \\
6.66 & 75.35 & 24.65 \\
7.00 & 76.41 & 23.59 \\
7.30 & 55.25 & 44.75 \\
7.70 & 51.66 & 48.34 \\
7.83 & 52.75 & 47.25 \\
\hline
\end{tabular}
rhamnosyltransferases or on the synthesis of a specific glycolipid transporter channel, or even on the synthesis of L-rhamnose in P. aeruginosa (Olvera et al., 1999). Escherichia coli represents an example in which various enzymes and periplasmic proteins are expressed in a $\mathrm{pH}$-dependent mechanism (Stancik et al. 2002). In any case, the possibility of obtaining a product with distinct percentages of rhamnolipid types synthesized by the appropriate choice of $\mathrm{pH}$ allows for 
187 188

different uses and applications for this natural formulation. Indeed, different rhamnolipid types or their mixtures present emulsifying activity, critical micellar concentration, hydrophobicity or bioavailabilities distinct from one other (Mata-Sandoval et al., 1999). Costa et al. (2010), for example, observed different CMC, emulsifying activity and interfacial tension values when they compared two rhamnolipid preparations with distinct proportions of mono and dirhamnolipids species.

From the viewpoint of quantitative analysis, the effect of the $\mathrm{pH}$ of the culture medium on total rhamnolipid synthesis by $P$. aeruginosa PA1 demonstrated that the most productive $\mathrm{pH}$ value was 7.0 (Figure 2). Guerra-Santos et al. (1984) found that rhamnolipid production by $P$. aeruginosa cultivated in glucose peaked at $\mathrm{pH}$ values ranging from 6.0 to 6.5 and decreased at values higher than 7.0. Jamal et al. (2014) achieved a maximum rhamnolipids yield (4.44 g.L-1) at a $\mathrm{pH}$ level of 7.33 using glycerol as the carbon source and $\mathrm{NaNO}_{3}$ as the nitrogen source.

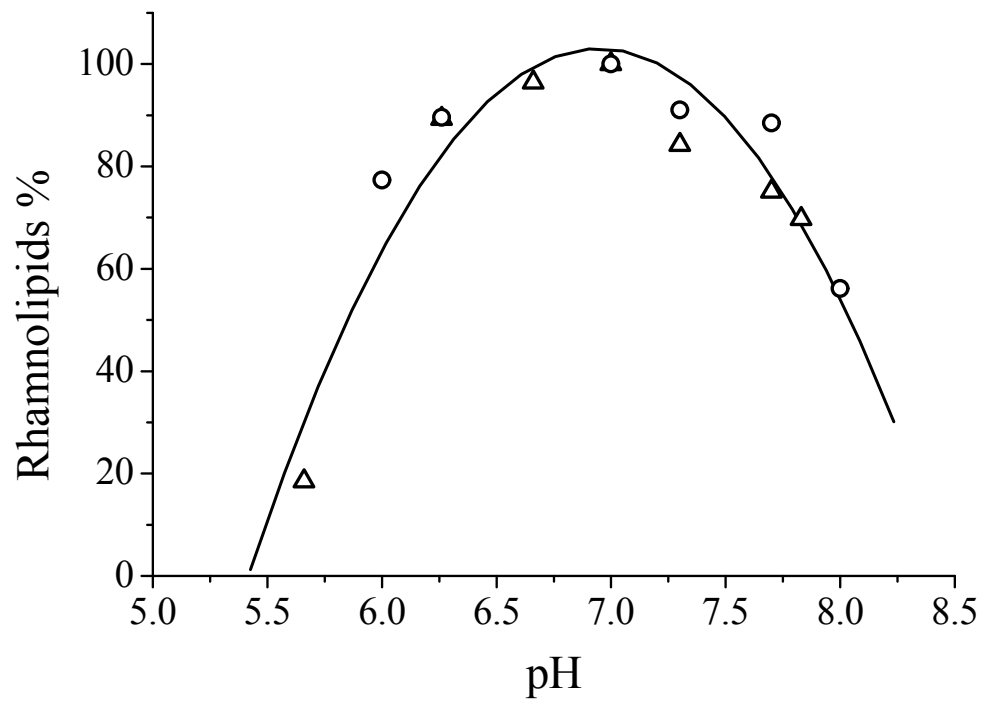

Figure 2: Variation of rhamnolipid synthesis as a function of the $\mathrm{pH}$ of the culture medium. The triangles and circles correspond to independent experiments. 


\section{Use of recycled $P$. aeruginosa spent culture medium}

for a 120-hour period (later stationary phase), was used to induce rhamnolipid production. The

Diggle et al., 2003).

The addition of spent medium containing endogenous autoinducers at the start of new $P$.

217 to $5 \%$ and from 5 to $15 \%$ (Table 2 ).

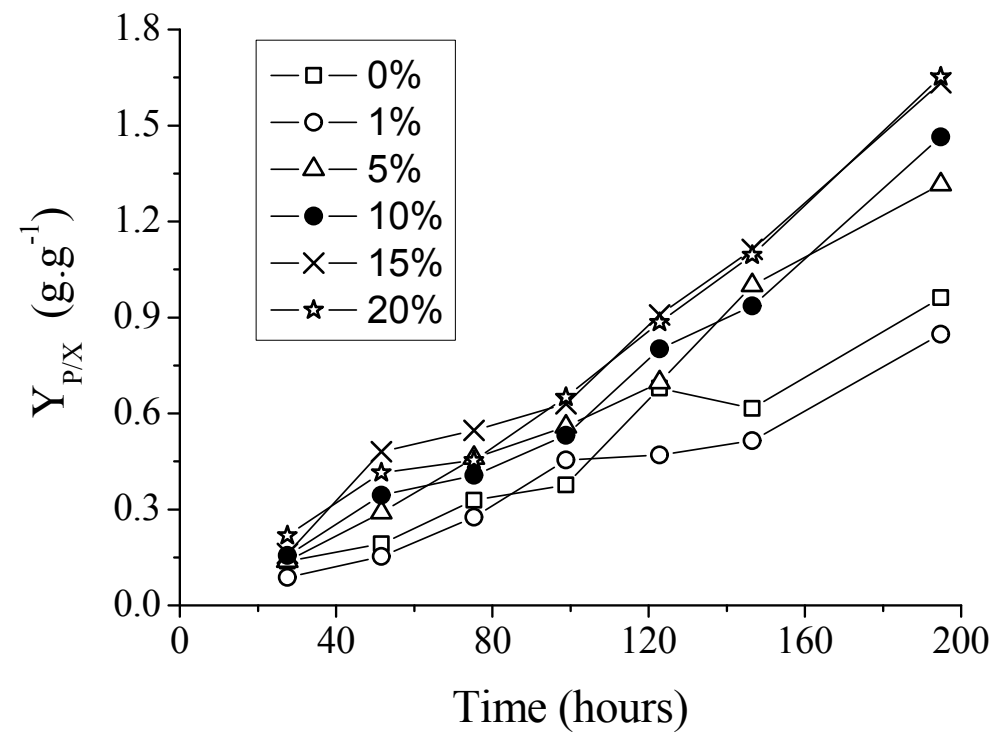


219 Figure 3: Progress curves of yield coefficient $Y_{P / X}$ in culture medium with different

\begin{tabular}{lcccccc}
\hline \multicolumn{1}{c}{ Parameters } & $\mathbf{0 \%}$ & $\mathbf{1 \%}$ & $\mathbf{5 \%}$ & $\mathbf{1 0 \%}$ & $\mathbf{1 5 \%}$ & $\mathbf{2 0 \%}$ \\
\hline$\Delta$ Rhamnolipids $\left(\mathrm{g} \mathrm{L}^{-1}\right)$ & 4.79 & 4.50 & 7.85 & 8.09 & 8.83 & 9.39 \\
$\Delta$ Biomass $\left(\mathrm{g} \mathrm{L}^{-1}\right)$ & 4.98 & 5.31 & 5.96 & 5.53 & 5.40 & 5.68 \\
$\mathrm{Y}_{\mathrm{P} / \mathrm{X}}\left(\mathrm{g} \mathrm{g}^{-1}\right)$ & 0.96 & 0.85 & 1.32 & 1.46 & 1.63 & 1.65 \\
$\mathrm{Y}_{\mathrm{P} / \mathrm{S}}\left(\mathrm{g} \mathrm{g}^{-1}\right)$ & 0.43 & 0.33 & 0.32 & 0.32 & 0.36 & 0.38 \\
$\mathrm{Q}_{\mathrm{P}}\left(\mathrm{g} \mathrm{L}^{-1} \mathrm{~h}^{-1}\right)$ & 0.027 & 0.026 & 0.044 & 0.047 & 0.051 & 0.054 \\
$\mathrm{Q}_{\mathrm{S}}\left(\mathrm{g} \mathrm{L}^{-1} \mathrm{~h}^{-1}\right)$ & 0.014 & 0.012 & 0.021 & 0.028 & 0.029 & 0.031
\end{tabular}

The addition of spent culture medium to the new $P$. aeruginosa PA1 culture also increased the volumetric glycerol consumption rate $\left(\mathrm{Q}_{\mathrm{S}(\mathrm{Gly})}\right)$ (Table 2). This fact suggests that the addition of endogenous autoinducers would also alter the metabolic rate of nutrients that, in the final analysis, would be coupled to the synthesis of the precursors for rhamnolipid production. The volumetric rhamnolipids production rate $\left(\mathrm{Q}_{\mathrm{P}}\right)$ was also favored by the addition of endogenous autoinducers (Table 2).

Table 2: Process parameters of rhamnolipid production by $P$. aeruginosa PA1 in culture medium supplemented with different percentages of spent medium containing endogenous autoinducers.

SRhamnolipids: difference between final and initial rhamnolipid concentration; $\Delta$ Biomass: difference between final and initial cellular concentration; $\mathbf{Y}_{\mathbf{P} / \mathbf{X}}$ : yield of product synthesized per unit of cell mass produced; $\mathbf{Y}_{\mathbf{P} / \mathbf{s}}$ : yield of product synthesized per unit of substrate consumed; $\mathbf{Q}_{\mathbf{P}}$ : volumetric rhamnolipids production rate; $\mathbf{Q}_{\mathbf{S}(\mathbf{G l y})}$ : volumetric glycerol consumption rate. 

specific rate of rhamnolipids synthesis, were plotted against the log values of the spent culture 240 medium concentration and are presented in Figure 4. This graph permits one to clearly observe 241 that the increase in the production of rhamnolipids was due to an increase in the capacity of the microorganisms to synthesize rhamnolipids. These results suggest that the amount of spent culture medium added at the beginning of cultivation probably contributed to the increase in the synthesis of rhamnosiltransferases because the natural unfolding of the quorum sensing system, which is responsible for the transcriptional regulation of rhamnolipid synthesis in presence of endogenous autoinducers.

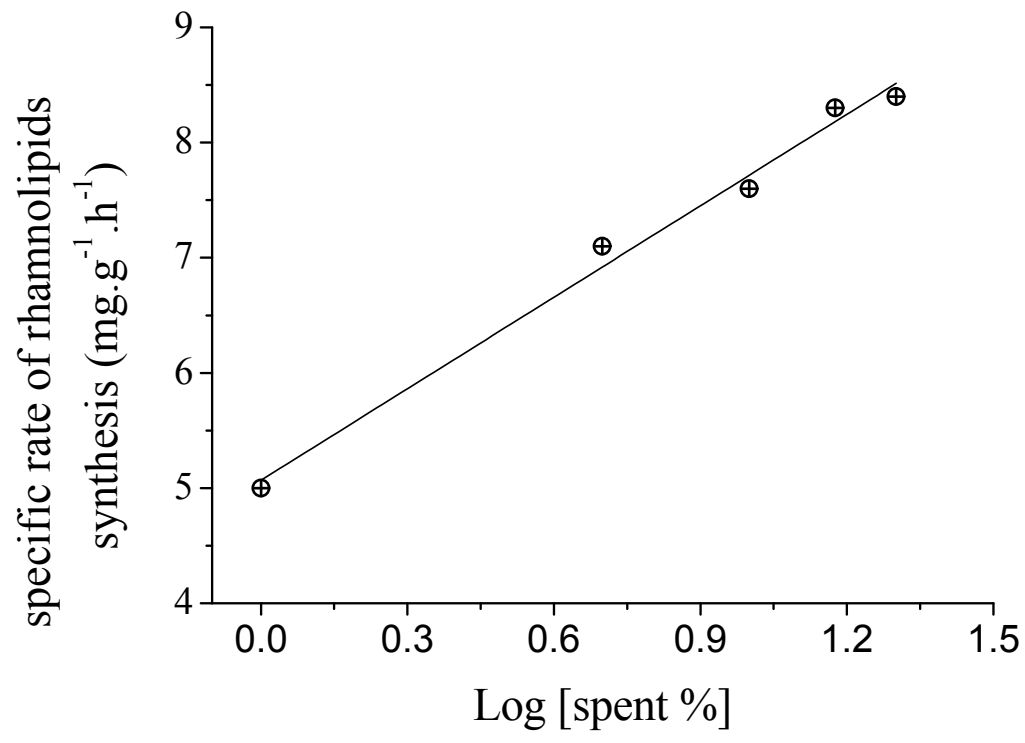

Figure 4: Relation between the specific rate of rhamnolipid synthesis and the addition of different proportions of $120 \mathrm{~h}$-old $P$. aeruginosa spent culture medium. 

254 rhamnolipids and was chosen to circumvent a possible negative effect, observed by Santa Anna 255 et al. (2002), on the assimilation of nutrients when the culture medium contains glycerol 256 concentrations higher than $3 \%$. In addition, a process driven by fed-batch can control and 257 maintain the nutrient limits already established as being favorable for rhamnolipid synthesis 258 (Desai and Banat, 1997; Chayabutra et al., 2000; Xavier et al., 2011). experiment, in which only water was fed to the medium, the carbon source (glycerol) and nitrogen source $\left(\mathrm{NaNO}_{3}\right)$ present at the beginning were totally consumed after approximately 50 and 24 hours of cultivation, respectively (Figures 5A and 5B).

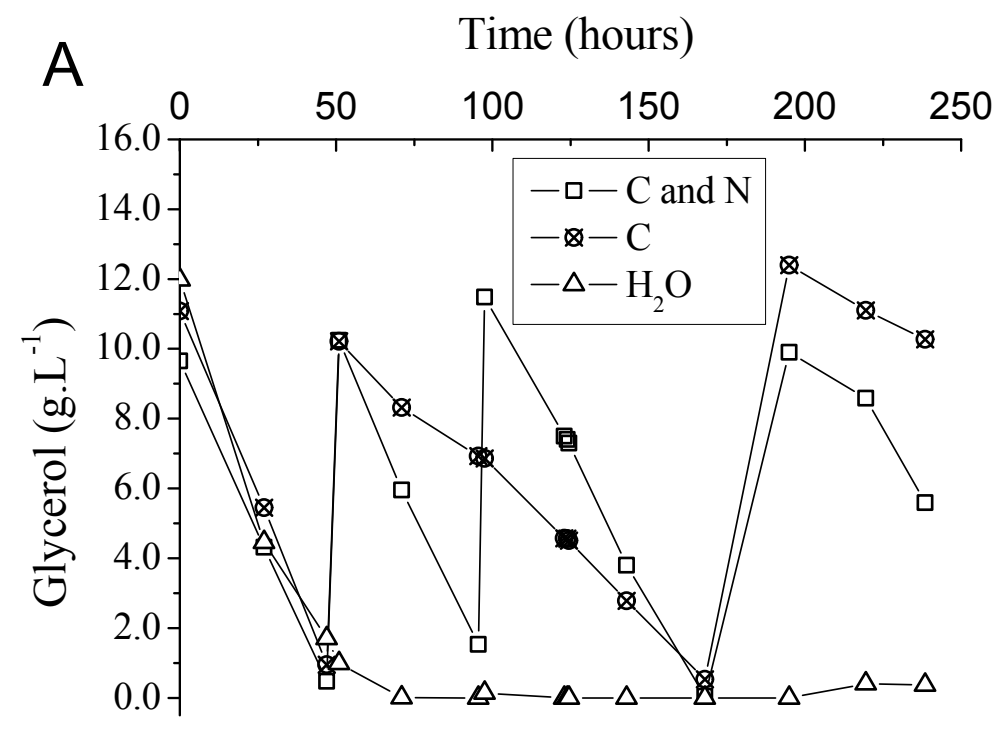




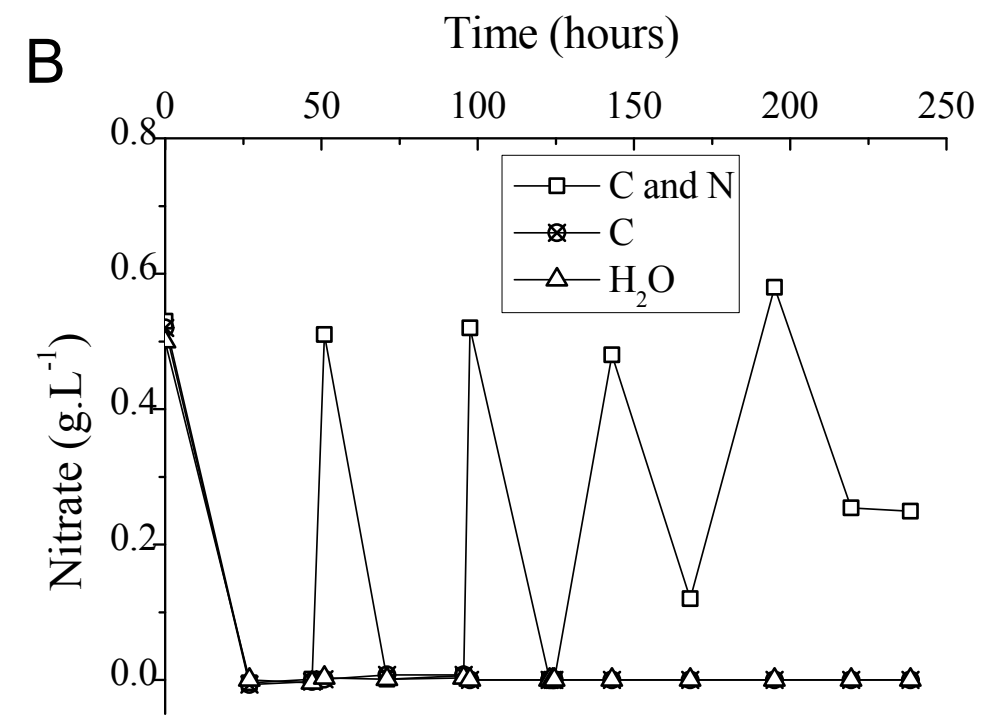

265

266

267

Figure 5: Progress curve of glycerol (A) and nitrate (B) consumption during the fed-batch process using different feeding strategies. $\mathrm{C}$ and $\mathrm{N}-$ fed with carbon and nitrogen sources together. $\mathrm{C}$ - fed only with the carbon source. $\mathrm{H}_{2} \mathrm{O}$ - fed with water instead of nutrients.

Although the consumption of the nitrogen source $\left(\mathrm{NaNO}_{3}\right)$ occurred in shorter time intervals than glycerol consumption (Figure 5A and 5B), the addition of a solution containing glycerol and nitrate was performed as a function of the consumption of the carbon source (Figure 5A). At 143 hours after the beginning of the process, the volumetric glycerol consumption rate decreased from $195 \mathrm{mg} \cdot \mathrm{L}^{-1} \cdot \mathrm{h}^{-1}$ to $162 \mathrm{mg} \cdot \mathrm{L}^{-1} \cdot \mathrm{h}^{-1}$. Because of this decay, only sodium nitrate was added at this time to the flask originally fed with carbon and nitrogen sources with the objective of maintaining the frequency of nitrate addition. The volumetric glycerol consumption rate $\left(\mathrm{Q}_{\mathrm{S}(\mathrm{Gly})}\right)$ was higher in the presence of a nitrogen source (Table 3). This fact becomes apparent when the curves of glycerol consumption are compared with one another, considering the process in which glycerol and nitrate are added together and the process in which only glycerol was added (Figure 5A). It is reasonable to assume that the enzymatic machinery involved in 
281 glycerol metabolism, as well as in rhamnolipid biosynthesis, depends on the assimilation of 282 nitrogen and its conversion into catalytic proteins.

Table 3: Process parameters observed in fed batch processes under different feeding conditions.

\begin{tabular}{lccc}
\hline Parameters & $\mathbf{C}+\mathbf{N}$ & $\mathbf{C}$ & $\mathbf{H}_{\mathbf{2}} \mathbf{O}$ \\
\hline$\Delta$ Rhamnolipids $\left(\mathrm{g} \mathrm{L}^{-1}\right)$ & 10.93 & 7.76 & 2.88 \\
$\Delta$ Biomass $\left(\mathrm{g} \mathrm{L}^{-1}\right)$ & 4.78 & 3.34 & 2.41 \\
$\mathrm{Y}_{\mathrm{P} / \mathrm{X}}\left(\mathrm{g} \mathrm{g}^{-1}\right)$ & 2.29 & 2.32 & 1.19 \\
$\mathrm{Y}_{\mathrm{P} / \mathrm{S}}\left(\mathrm{g} \mathrm{g}^{-1}\right)$ & 0.33 & 0.35 & 0.21 \\
$\mathrm{Q}_{\mathrm{P}}\left(\mathrm{g} \mathrm{L}^{-1} \mathrm{~h}^{-1}\right)$ & 0.047 & 0.033 & 0.027 \\
$\mathrm{Q}_{\mathrm{S}(\mathrm{Gly})}\left(\mathrm{g} \mathrm{L}^{-1} \mathrm{~h}^{-1}\right)$ & 0.168 & 0.073 & 0.197 \\
$\mathrm{Q}_{\mathrm{S}(\mathrm{NO} 3)}\left(\mathrm{g} \mathrm{L}^{-1} \mathrm{~h}^{-1}\right)$ & 0.027 & 0.027 & 0.027
\end{tabular}

$\Delta$ Rhamnolipids: difference between final and initial rhamnolipid concentration; $\Delta$ Biomass: difference between

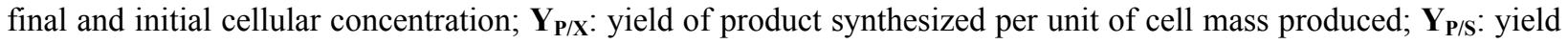
of product synthesized per unit of substrate consumed; $\mathbf{Q}_{\mathbf{P}}$ : volumetric rhamnolipids production rate; $\mathbf{Q}_{\mathbf{S}(\mathbf{g l y})}$ : volumetric glycerol consumption rate; $\mathbf{Q}_{\mathbf{S}(\mathrm{NO})}$ : volumetric nitrate consumption rate. The parameters for the condition " $\mathrm{H}_{2} \mathrm{O}$ " were calculated at $100 \mathrm{~h}$ of culture.

Ochsner et al. (1995) observed that the activity of the rhamnosyltransferase in $P$. aeruginosa during cultivation in a nitrogen-limiting medium containing glycerol as the carbon source was the highest at the beginning of the stationary phase and declined to zero in the late stationary phase. We suggest that exhaustion of the nitrogen source would limit not only cellular growth, but also the maintenance of the enzymatic machinery, mainly that involved in the metabolic pathways for rhamnolipid synthesis. In the present work, when the process of rhamnolipids production was simultaneously fed with carbon and nitrogen sources, a higher cell yield and volumetric productivity of rhamnolipids was achieved (Table 3). 
On the basis of the feeding conditions, together with the control experiment (without 300 feeding), one can conclude that the exhaustion of carbon and nitrogen sources interrupted the $P$. aeruginosa growth (Figure 6A) and the rhamnolipid synthesis (Figure 6B) sooner (at 72 hours after initiating the cultivation). On the other hand, feeding the system with only glycerol led to an improvement when compared with the simple batch (Figure 6A) and resulted in higher $\mathrm{Y}_{\mathrm{P} / \mathrm{X}}$ and $\mathrm{Y}_{\mathrm{P} / \mathrm{S}}$ values (Table 3). Furthermore, the feeding condition with both sources of nutrients (carbon and nitrogen) resulted in an even greater increase in both the biomass produced (Figure 6A) and the volumetric productivity, reaching a rhamnolipid production value $40 \%$ higher (Table 3 ) 

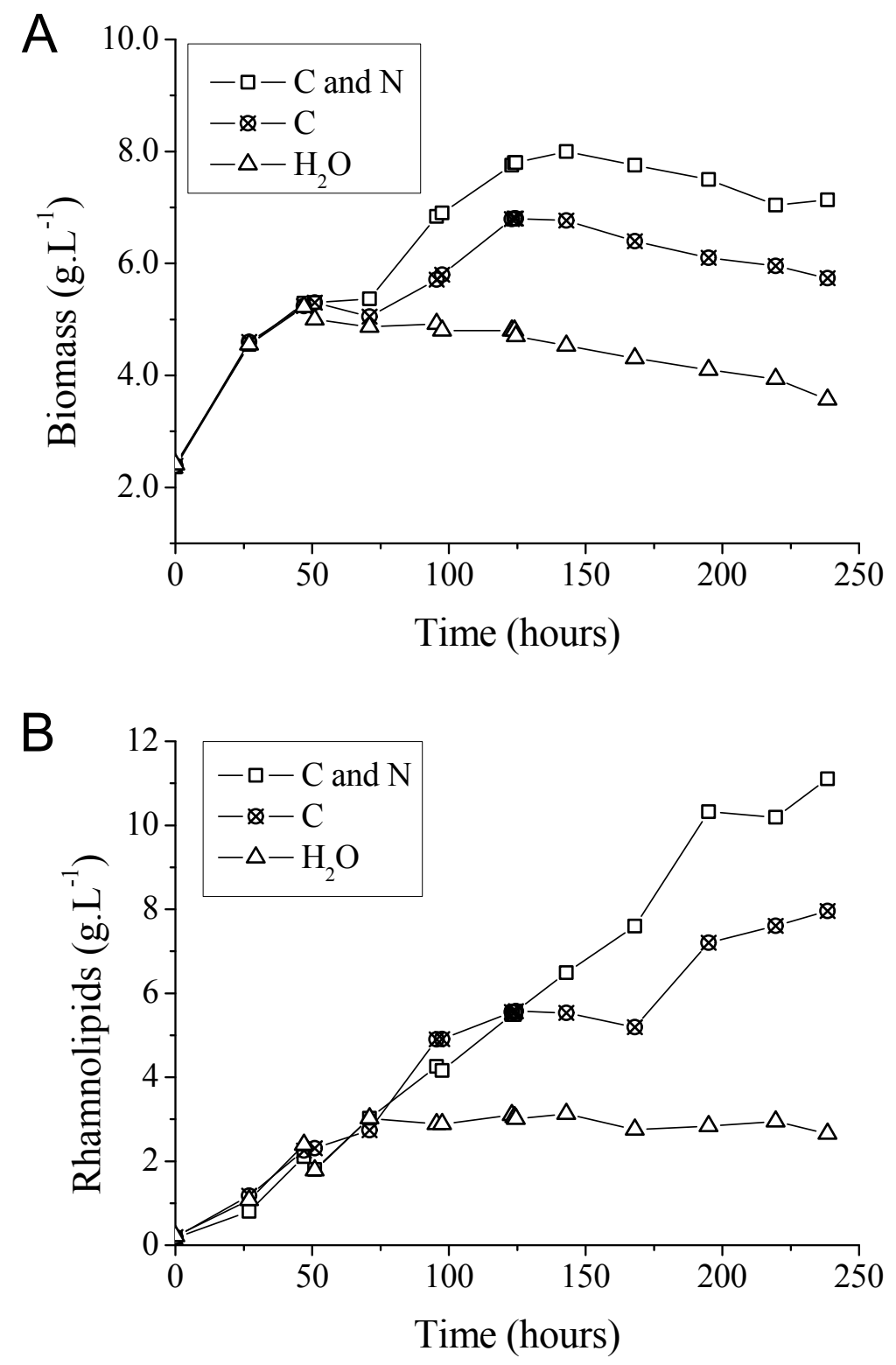

Figure 6: $P$. aeruginosa growth curves (A) and time course of rhamnolipid production (B) in the fed-batch process using different feeding strategies. $\mathrm{C}$ and $\mathrm{N}-$ fed with carbon and nitrogen sources together. $\mathrm{C}$ - fed only with the carbon source. $\mathrm{H}_{2} \mathrm{O}-$ fed with water instead of nutrients.

After 125 hours from the start of the process, cell growth stopped in the fed-batch system with both sources of nitrogen and carbon and in the system only fed with carbon source (Figures 
$3166 \mathrm{~A}$ and $6 \mathrm{~B})$. It is possible that the limitation of other nutrients has occurred at this point, such as

317 trace elements or oxygen. However, the production of rhamnolipids remained active mainly 318 when fed simultaneously with nitrate and glycerol. This behavior characterizes a semi-growth 319 associated profile.

\section{Conclusion} rhamnolipids by $P$. aeruginosa PA1, selective synthesis of different types of rhamnolipids caused by certain $\mathrm{pH}$ ranges appeared as an unexpected and timely result. The reutilization or recycling of culture medium containing endogenous autoinducers of the quorum sensing system produced by $P$. aeruginosa in new culture medium for the production of rhamnolipids was very 327 effective in the induction of rhamnolipid synthesis. A two-fold increase in volumetric productivity was obtained using this strategy. The fed-batch experiment using the limitation of the carbon and nitrogen source was successful and could be employed along with an appropriate formulation of the cultivation conditions (micronutrients, $\mathrm{pH}$, supplementary autoinducers)

\section{Acknowledgments}




\section{References}

American Chemical Society, American Chemical Society. (eds.) 2006. Reagent chemicals: specifications and procedures: American Chemical Society specifications, official from January 1, 2006. Washington, DC : New York: American Chemical Society ; Oxford University Press.

Araujo LV de, Freire DMG, Nitschke M. 2013. Biossurfactantes: propriedades anticorrosivas, antibiofilmes e antimicrobianas. Química Nova 36:848-858. DOI: 10.1590/S010040422013000600019.

Bognolo G. 1999. Biosurfactants as emulsifying agents for hydrocarbons. Colloids and Surfaces A: Physicochemical and Engineering Aspects 152:41-52. DOI: 10.1016/S09277757(98)00684-0.

Chayabutra C, Wu J, Ju L-K. 2001. Rhamnolipid production by Pseudomonas aeruginosa under denitrification: Effects of limiting nutrients and carbon substrates. Biotechnology \& Bioengineering 72:25-33. DOI: 10.1002/1097-0290(20010105)72:1<25::AIDBIT4>3.0.CO;2-J.

Clarke KG, Ballot F, Reid SJ. 2010. Enhanced rhamnolipid production by Pseudomonas aeruginosa under phosphate limitation. World Journal of Microbiology and Biotechnology 26:2179-2184. DOI: 10.1007/s11274-010-0402-y.

Costa SGVAO, Nitschke M, Lépine F, Déziel E, Contiero J. 2010. Structure, properties and applications of rhamnolipids produced by Pseudomonas aeruginosa L2-1 from cassava wastewater. Process Biochemistry 45:1511-1516. DOI: 10.1016/j.procbio.2010.05.033.

Desai JD, Banat IM. 1997. Microbial production of surfactants and their commercial potential. Microbiology and molecular biology reviews: MMBR 61:47-64. 
Diggle SP, Winzer K, Chhabra SR, Worrall KE, Cámara M, Williams P. 2003. The Pseudomonas aeruginosa quinolone signal molecule overcomes the cell densitydependency of the quorum sensing hierarchy, regulates rhl-dependent genes at the onset of stationary phase and can be produced in the absence of LasR. Molecular Microbiology 50:29-43.

DuBois M, Gilles KA, Hamilton JK, Rebers PA, Smith F. 1956. Colorimetric Method for Determination of Sugars and Related Substances. Analytical Chemistry 28:350-356. DOI: $10.1021 / \mathrm{ac} 60111 \mathrm{a} 017$.

Fuqua C, Greenberg EP. 1998. Self perception in bacteria: quorum sensing with acylated homoserine lactones. Current Opinion in Microbiology 1:183-189.

Galkin NB, Abedalabas M, Pachomova EY, Filipova TO. 2014. The effect of Pseudomonas aeruginosa signal quinolone on the rhamnolipids and rhamnosyltransferase 2 activity. European Scientific Journal 3:223-228.

Glick R, Gilmour C, Tremblay J, Satanower S, Avidan O, Déziel E, Greenberg EP, Poole K, Banin E. 2010. Increase in rhamnolipid synthesis under iron-limiting conditions influences surface motility and biofilm formation in Pseudomonas aeruginosa. Journal of Bacteriology 192:2973-2980. DOI: 10.1128/JB.01601-09.

Guerra-Santos L, Käppeli O, Fiechter A. 1986. Dependence of Pseudomonas aeruginosa continous culture biosurfactant production on nutritional and environmental factors. Applied Microbiology and Biotechnology 24. DOI: 10.1007/BF00250320.

Irfan-Maqsood M, Seddiq-Shams M. 2014. Rhamnolipids: Well-Characterized Glycolipids with Potential Broad Applicability as Biosurfactants. Industrial Biotechnology 10:285-291. DOI: 10.1089/ind.2014.0003. 
382 Ishigami Y, Gama Y, Sano Y, Lang S, Wagner F. 1994. Interfacial and micellar behavior of 383 glucose lipid. Biotechnology Letters 16:593-598. DOI: 10.1007/BF00128606.

Jamal A, Qureshi MZ, Ali N, Ali MI, Hameed A. 2014. Enhanced Production of Rhamnolipids by Pseudomonas aeruginosa JQ927360 Using Response Surface Methodology. Asian Journal of Chemistry 26. DOI: 10.14233/ajchem.2014.15851.

Kesting W, Tummuscheit M, Schacht H, Schollmeyer E. 1996. Ecological washing of textiles with microbial surfactants. In: Jacobasch H-J ed. Interfaces, Surfactants and Colloids in Engineering. Darmstadt: Steinkopff, 125-130.

Kitamoto D, Isoda H, Nakahara T. 2002. Functions and potential applications of glycolipid biosurfactants--from energy-saving materials to gene delivery carriers. Journal of Bioscience and Bioengineering 94:187-201.

Kronemberger FA, Anna LMMS, Fernandes ACLB, Menezes RR, Borges CP, Freire DMG. 2007. Oxygen-controlled Biosurfactant Production in a Bench Scale Bioreactor. In: Adney WS, McMillan JD, Mielenz J, Klasson KT eds. Biotechnology for Fuels and Chemicals. Totowa, NJ: Humana Press, 401-413.

Lang S, Wullbrandt D. 1999. Rhamnose lipids - biosynthesis, microbial production and application potential. Applied Microbiology and Biotechnology 51:22-32. DOI: $10.1007 / \mathrm{s} 002530051358$.

Mata-Sandoval JC, Karns J, Torrents A. 1999. High-performance liquid chromatography method for the characterization of rhamnolipid mixtures produced by Pseudomonas aeruginosa UG2 on corn oil. Journal of Chromatography A 864:211-220. DOI: 10.1016/S00219673(99)00979-6.

Mata-Sandoval JC, Karns J, Torrents A. 2001. Effect of nutritional and environmental conditions 
on the production and composition of rhamnolipids by $P$. aeruginosa UG2. Microbiological Research 155:249-256. DOI: 10.1016/S0944-5013(01)80001-X.

Mulligan CN, Mahmourides G, Gibbs BF. 1989. The influence of phosphate metabolism on biosurfactant production by Pseudomonas aeruginosa. Journal of Biotechnology 12:199209. DOI: $10.1016 / 0168-1656(89) 90041-2$.

Nakata K, Yoshimoto A, Yamada Y. 1998. Correlation between autoinducers and rhamnolipids production by Pseudomonas aeruginosa IFO 3924. Journal of Fermentation and Bioengineering 86:608-610. DOI: 10.1016/S0922-338X(99)80016-6.

Ochsner UA, Hembach T, Fiechter A. 1995. Production of rhamnolipid biosurfactants. In: Downstream Processing Biosurfactants Carotenoids. Berlin, Heidelberg: Springer Berlin Heidelberg, 89-118.

Ochsner UA, Koch AK, Fiechter A, Reiser J. 1994. Isolation and characterization of a regulatory gene affecting rhamnolipid biosurfactant synthesis in Pseudomonas aeruginosa. Journal of Bacteriology 176:2044-2054.

Ochsner UA, Reiser J. 1995. Autoinducer-mediated regulation of rhamnolipid biosurfactant synthesis in Pseudomonas aeruginosa. Proceedings of the National Academy of Sciences 92:6424-6428. DOI: 10.1073/pnas.92.14.6424.

Olvera C, Goldberg JB, Sánchez R, Soberón-Chávez G. 1999. The Pseudomonas aeruginosa algC gene product participates in rhamnolipid biosynthesis. FEMS microbiology letters 179:85-90.

Pesci EC, Pearson JP, Seed PC, Iglewski BH. 1997. Regulation of las and rhl quorum sensing in Pseudomonas aeruginosa. Journal of Bacteriology 179:3127-3132.

Rahim R, Ochsner UA, Olvera C, Graninger M, Messner P, Lam JS, Soberón-Chávez G. 2001. 
Cloning and functional characterization of the Pseudomonas aeruginosa rhlC gene that encodes rhamnosyltransferase 2, an enzyme responsible for di-rhamnolipid biosynthesis. Molecular Microbiology 40:708-718.

Rahman KS., Banat I., Thahira J, Thayumanavan T, Lakshmanaperumalsamy P. 2002.

Bioremediation of gasoline contaminated soil by a bacterial consortium amended with poultry litter, coir pith and rhamnolipid biosurfactant. Bioresource Technology 81:25-32. DOI: $10.1016 / \mathrm{S} 0960-8524(01) 00105-5$.

Randhawa KKS, Rahman PKSM. 2014. Rhamnolipid biosurfactantsâ€”past, present, and future scenario of global market. Frontiers in Microbiology 5. DOI: 10.3389/fmicb.2014.00454.

Reis RS, Pereira AG, Neves BC, Freire DMG. 2011. Gene regulation of rhamnolipid production in Pseudomonas aeruginosa - A review. Bioresource Technology 102:6377-6384. DOI: 10.1016/j.biortech.2011.03.074.

Santa Anna LM, Sebastian GV, Menezes EP, Alves TLM, Santos AS, Pereira Jr. N, Freire DMG. 2002. Production of biosurfactants from Pseudomonas aeruginosa PA1 isolated in oil environmental. Brazilian Journal of Chemical Engineering 10:159-166.

Santa Anna LM, Sebastian GV, Pereira, Jr N, Alves TLM, Menezes EP, Freire DMG. 2001. Production of Biosurfactant from a New and Promising Strain of Pseudomonas aeruginosa PA1. Applied Biochemistry and Biotechnology 91-93:459-468. DOI: 10.1385/ABAB:91-93:1-9:459.

Schenk T, Schuphan I, Schmidt B. 1995. High-performance liquid chromatographic determination of the rhamnolipids produced by Pseudomonas aeruginosa. Journal of Chromatography A 693:7-13. DOI: 10.1016/0021-9673(94)01127-Z.

Sinumvayo JP. 2015. Agriculture and Food Applications of Rhamnolipids and its Production by 
Pseudomonas aeruginosa. Journal of Chemical Engineering \& Process Technology 06. DOI: $10.4172 / 2157-7048.1000223$.

Sousa JR, Costa Correia JA, Almeida JGL, Rodrigues S, Pessoa ODL, Melo VMM, Gonçalves LRB. 2011. Evaluation of a co-product of biodiesel production as carbon source in the production of biosurfactant by P. aeruginosa MSIC02. Process Biochemistry 46:18311839. DOI: 10.1016/j.procbio.2011.06.016.

Stancik LM, Stancik DM, Schmidt B, Barnhart DM, Yoncheva YN, Slonczewski JL. 2002. pHdependent expression of periplasmic proteins and amino acid catabolism in Escherichia coli. Journal of Bacteriology 184:4246-4258.

Syldatk C, Lang S, Matulovic U, Wagner F. 1985. Production of four interfacial active rhamnolipids from n-alkanes or glycerol by resting cells of Pseudomonas species DSM 2874. Zeitschrift Für Naturforschung. Section C: Biosciences 40:61-67.

Torrens JL, Herman DC, Miller-Maier RM. 1998. Biosurfactant (Rhamnolipid) Sorption and the Impact on Rhamnolipid-Facilitated Removal of Cadmium from Various Soils under Saturated Flow Conditions. Environmental Science \& Technology 32:776-781. DOI: 10.1021/es970285o.

Van Dyke MI, Couture P, Brauer M, Lee H, Trevors JT. 1993. Pseudomonas aeruginosa UG2 rhamnolipid biosurfactants: structural characterization and their use in removing hydrophobic compounds from soil. Canadian Journal of Microbiology 39:1071-1078. DOI: $10.1139 / \mathrm{m} 93-162$.

Williams P, Camara M, Hardman A, Swift S, Milton D, Hope VJ, Winzer K, Middleton B, Pritchard DI, Bycroft BW. 2000. Quorum sensing and the population-dependent control of virulence. Philosophical Transactions of the Royal Society B: Biological Sciences 
475 Xavier JB, Kim W, Foster KR. 2011. A molecular mechanism that stabilizes cooperative secretions in Pseudomonas aeruginosa: Metabolic prudence in P. aeruginosa. Molecular Microbiology 79:166-179. DOI: 10.1111/j.1365-2958.2010.07436.x. 